\title{
Direct Cyclodextrin Based Powder Extrusion 3D Printing for One-step Production of the BCS Class II Model Drug Niclosamide
}

\section{Monica Pistone}

Università degli Studi di Bari "Aldo Moro"

Giuseppe Francesco Racaniello

Università degli Studi di Bari "Aldo Moro"

Ilaria Arduino

Università degli Studi di Bari "aldo Moro"

Valentino Laquintana

Università degli Studi di Bari "aldo Moro"

Antonio Lopalco

Università degli Studi di Bari "ALdo Moro"

Annalisa Cutrignelli

Università degli Studi di Bari "Aldo Moro"

Rosanna Rizzi

CNR Institut of crystallography, Bari

Massimo Franco

Università degli Studi di Bari "Aldo Moro"

Angela Lopedota

Università degli Studi di Bari "Aldo Moro"

Nunzio Denora ( $\nabla$ nunzio.denora@uniba.it)

Università degli Studi di Bari https://orcid.org/0000-0002-7756-7828

\section{Research Article}

Keywords: 3D printing, Direct Powder Extrusion Printing, 3DForMe® printer, Repositioning Niclosamide, Personalized medicines, Amorphous solid dispersions, Sustained release

Posted Date: October 21st, 2021

DOI: https://doi.org/10.21203/rs.3.rs-965993/v1

License: (c) (1) This work is licensed under a Creative Commons Attribution 4.0 International License.

Read Full License 
Version of Record: A version of this preprint was published at Drug Delivery and Translational Research on February 9th, 2022. See the published version at https://doi.org/10.1007/s13346-022-01124-7. 


\section{Abstract}

Niclosamide (NCS) is a drug that has been used as an anthelmintic and anti-parasitic active principle for about 40 years. Recently, some studies have highlighted its potential in treating various tumors, allowing a repositioning of this drug. Despite its potential, NCS is a Biopharmaceutical Classification System (BCS) Class II drug, and is consequently characterised by low aqueous solubility, poor dissolution rate and reduced bioavailability, which limits its applicability. In this work, we utilize a very novel technique, Direct Powder Extrusion (DPE) 3D printing, which overcomes the limitations of previously used techniques (Fused Deposition Modelling, FDM) to achieve direct extrusion of pharmaceutical grade powder mixtures consisting of NCS, hydroxypropyl methylcellulose (HPMC, Affinisol 15 LV), hydroxypropyl-b-cyclodextrin (HP- $\beta-C D)$ and polyethylene glycol (PEG) 6000. For the first time, direct printing of powder blends containing HP- $\beta$-CD was explored. For all tablets, in vitro dissolution studies showed sustained drug release over 48 hours, but for tablets containing HP- $\beta-C D$, the release was faster. Solid-state characterisation studies showed that during extrusion, the drug lost its crystal structure and was evenly distributed within the polymer matrix. All printed tablets exhibited good mechanical and physical features and guarantee stability of the drug content for up to 3 months. This innovative printing technique has demonstrated the possibility to produce personalised pharmaceutical dosage forms starting directly from powders, avoiding the use of filament used by FDM.

\section{Introduction}

Niclosamide (NCS) is a drug included in the World Health Organization's Model List of Essential Medicines [1] and has been approved in 1982 by the FDA as an anti-parasitic and anthelmintic active principle. In recent years, different biological activities have been attributed to this molecule, allowing a repositioning of this drug as a good candidate for the treatment of tumor disease [2]. Latest studies, conducted both in vitro and in vivo, have shown that NCS can act as an anticancer drug against colon, lung, breast, and prostate cancer $[3,4]$, and in accordance with the dose used in clinical studies $[5,6]$ and by applying the method of normalizing Body Surface Area (BSA) [7], proposed by the Food and Drug Administration, the therapeutic dose of NCS is around $50 \mathrm{mg}$ for a person weighing $70 \mathrm{~kg}$. This drug has recently been described as a potent Stat3 inhibitor capable of suppressing Stat3 phosphorylation at Tyr705 and transcript activity [8,9], moreover a correlation between Stat3 and the accumulation of myeloid-derived suppressor cells (MDSCs) in tumor-bearing mice has been demonstrated [10-12]. Treatment with NCS has been proven to reduce the number of MDSCs, which promote tumor growth and metastasis formation in breast cancer patients. Despite its potential, expectations of the NCS should be enhanced by a realistic and rational assessment, as the repositioning process requires an improvement in its chemical and physical characteristics. Indeed, NCS is a drug described by poor aqueous solubility and reduced dissolution and absorption rate [4], being a class II drug according to the Biopharmaceutics Classification System (BCS). In this regard, there are several strategies to satisfy this need, including the conversion of a drug's solid state from crystalline to amorphous $[13,14]$. The use of a drug in an amorphous state involves its stabilization in a formulation, which can be obtained by generating an 
amorphous solid dispersion (ADS). There are numerous methods for obtaining ADS, but the most investigated one, in recent decades, is the hot melt extrusion (HME), a continuous process in which temperature and pressure are applied to soften or melt the starting material $[15,16]$ forcing it through an orifice and producing new products with uniform shape and density [15]. This technique produces filaments that can be utilized for the preparation of personalized dosage forms by using threedimensional (3D) printing.

The 3D printing (3DP) is emerging as a very innovative technique capable of transforming a digital model, generated by computer-assisted design software (CAD), into a real product by the gradual layering of material [15]. For many years, 3D technologies have been employed in a broad range of research areas for the fast and cost-effective production of design models [17-19]. In the field of pharmaceutical applications, this revolutionary technology is growing in parallel with the concept of personalized medicine [20,21], which aims to adapt medical treatments to the needs and characteristics of individual patients $[22,23]$. There are many benefits that 3D printing provides including the sustainability, patentability, and the capacity to produce at lower costs [23]. In addition, 3D printing can enable a complete reorganization of galenic practice, specifically due to the small space required to set up the printing facility and extemporaneous production on demand [23]. Indeed, the real-time production offered by this technology overcomes the need for storage and the long-term stability of printed products. According to the American Society for Testing and Materials (ASTM) classification, there are seven different types of 3DP: in-tank photopolymerization, material jet, binder jet, material extrusion, powder bed casting, sheet lamination, and direct energy deposition [24]. The most widely used 3D printing technology is Fused Deposition Modeling (FDM) [25], which allows the extrusion of starting materials, in form of thermoplastic filaments obtained by HME, above their melting temperature. However, there are several limitations of the HME process, primarily the filament must satisfy numerous physical and mechanical parameters to be suitable as a starting material for FDM, thus limiting the choice of active compounds and excipients [26]. In addition, there may be complications with filament extrusion [27], especially when high drug dosages are requested, or degradation of active compounds due to high melting temperatures that may reduce the drug loading and release profile $[24,26]$. The possibility to overcome all these limitations is offered by Direct Powder Extrusion (DPE) 3DP. In fact, through this pioneering technology, it is possible to extrude material directly from pellets or powder using a single-screw extruder [24], so preparation of the filament by $\mathrm{HME}$ is not necessary and it is possible to extrude mixtures that could not be extruded by FDM. In order to repurpose NCS as a drug for the treatment of tumor diseases, and to overcome the limitations of its low solubility and poor dissolution and absorption rate, in this work sustained-release printed tablets by DPE have been developed using hydroxypropyl methylcellulose (HPMC, Affinisol $15 \mathrm{LV}$ ) as a carrier polymer, hydroxypropyl- $\beta$-cyclodextrin (HP- $\beta$-CD) as a solubilizing and complexing agent and polyethylene glycol (PEG) 6000 as a plasticizer. Cyclodextrins (CD) have been widely used as pharmaceutical excipients for many years, yet they are still very innovative due to their remarkable properties, including the ability to form inclusion complexes with poorly soluble drugs, thereby increasing their solubility $[28,29]$. The use of cyclodextrins in HME to enhance the solubility of class II BCS drugs is well documented [26,30], especially the application of ternary mixtures (drug, CD and 
polymer) where the polymer could improve the stability of the drug-CD complex [29, 31, 32]. However, despite numerous studies of $\mathrm{CD}$ extrusion, alone or in combination, by $\mathrm{HME}$, there are no references in the literature of $C D$ extrusion by DPE.

In this perspective, the aim of this study was to explore the use of an innovative technology, DPE 3DP, highlighting the ability, for the first time, to directly extrude powders containing HP- $\beta-C D$, and to overcome the pharmacokinetic limitations associated with NCS (class II BCS drug) such as low aqueous solubility and poor dissolution rate. Accordingly, NCS ASDs were manufactured as sustained release printed tablets from powder mixtures with different compositions. Solid-state characterization studies were carried out on the various mixtures and formulations obtained, as well as the study of drug dissolution profiles and evaluation of the stability of the 3D printed tablets.

\section{Materials And Methods \\ 2.1. Materials}

Niclosamide and Sodium Hydroxide were purchased from Sigma Aldrich - Merck (Darmstadt, GERMANY). Hydroxypropyl- $\beta$-cyclodextrin, (Cavasol W7, HP- $\beta$-CD with $M W=1540$, molar substitution degree $S D=7$ ) and Polyethylene Glycol 6000 and Micronized Talcum Powder (Ph. Eur. E 553b) were purchased from Farmalabor srl (Canosa di Puglia, ITALY). AFFINISOL ${ }^{\text {TM }}$ HPMC HME 15 LV (hydroxypropyl methylcellulose) was gifted by Pharma Solutions - Nutrition \& Biosciences Italy (Milano, ITALY). Aerosil 200 micronized silica was purchased from Fagron (Rotterdam, NETHERLANDS). Ethanol $96 \%$ vol was purchased from VWR Chemicals Italia (Milano, ITALY). Polysorbate 80 and Potassium Phosphate Dibasic were purchased from Honeywell Fluka Italia (Rodano, ITALY). For the analysis, distilled and purified water (conductivity of 18.2 M $\Omega . \mathrm{cm}$ at $23^{\circ} \mathrm{C}$ ) was obtained by the purification system Milli-Q (Purelab DI, MK2) (Elga, High Wycombe, UK).

\subsection{Quantitative Analysis of NCS}

For the quantitative analysis of NCS a PerkinElmer double-beam UV-visible spectrophotometer Lambda Bio 20 (Milan, Italy) was used, equipped with $10 \mathrm{~mm}$ path-length-matched quartz cells. Standard calibration curves were prepared at a wavelength of $340 \mathrm{~nm}$ using ethanol as solvent. A calibration straight line $\left(R^{2}=0.9999\right)$, in the concentration range between $0,305 \mu \mathrm{M}$ and $152,5 \mu \mathrm{M}$, was obtained.

\subsection{Preparation of powder blends}

Four samples constituted of polymer powder blends at different concentrations and a constant drug concentration (NCS 10\% w/w) were prepared. In each mixture, a cellulosic matrix, such as Affinisol HPMC HME 15 LV, was used in added PEG 6000 (blends 2 and 4) as plasticizer and, HP- $\beta$-CD (blends 3 and 4) to improve drug solubility were employed. The final composition of each mixture is shown in Table 1. 
Table 1

Composition of powder mixtures.

\begin{tabular}{|lllll|}
\hline Samples & NCS & HPMC & PEG 6000 & HP- $\beta-C D$ \\
\hline \multicolumn{5}{c}{$(\% \mathrm{w} / \mathrm{w})$} \\
Blend 1 & 10 & 90.00 & $/$ & $/$ \\
\hline Blend 2 & 10 & 85.50 & 4.50 & $/$ \\
\hline Blend 3 & 10 & 42.87 & $/$ & 47.13 \\
\hline Blend 4 & 10 & 40.73 & 2.14 & 47.13 \\
\hline
\end{tabular}

Each component was sieved three times through a $355 \mu \mathrm{m}$ mesh sieve to provide better dimensional uniformity and mixing of the powders. Next, the powders were mechanically stirred for approximately one hour at $67 \mathrm{rpm}$ using the Turbula Willy A. Bachofen $\mathrm{GmbH}$ (Nidderau, Germany). The resulting powder blends were dried overnight at $40^{\circ} \mathrm{C}$ in stove.

\subsection{Solid state characterization of powder mixtures}

The four powder blends were characterized in the solid state together with the pure drug and the physical blends consisting only of the excipients. They were studied by Fourier-transform infrared spectroscopy (FT-IR), differential scanning calorimetry (DSC) and powder X-ray diffractometry (PXRD). For FT-IR analysis, $\mathrm{KBr}$ pellets ( $2 \%$ of sample) were analysed by FT-IR 1600 Perkin Elmer spectrophotometer. Data were acquired between $4000 \mathrm{~cm}^{-1}$ and $400 \mathrm{~cm}^{-1}$. Thermal analyses by DSC of different samples were performed by a Mettler Toledo DSC822 instrument. About 5-10 mg of sample were heated in an aluminium pan with a $5^{\circ} \mathrm{C} / \mathrm{min}$ heating rate from $25^{\circ} \mathrm{C}$ to $280^{\circ} \mathrm{C}$ under $\mathrm{N}_{2}$ flow. An empty pan was used as a reference. The patterns were collected by using a Rigaku Rint2500 rotating $\mathrm{Cu}$ anode, working at 50 $\mathrm{kV}$ and $200 \mathrm{~mA}$ in Debye-Scherrer geometry. The diffractometer is equipped with an asymmetric Johansson $\mathrm{Ge}(111)$ crystal to select the monochromatic $\mathrm{CuKa}_{1}$ radiation $(\lambda=1.54056 \AA)$ and the silicon strip Rigaku D/teX Ultra detector. The range from 5 to $90^{\circ}(2 \vartheta)$ was collected with a $0.02^{\circ}(2 \vartheta)$ step size and counting time of $6 \mathrm{~s} / \mathrm{step}$. Each powder was introduced in a glass capillary of $0.5 \mathrm{~mm}$ of diameter and mounted on the axis of the goniometer. The capillary was rotated during the measurement to improve the randomization of the orientations of the individual crystallites to reduce the effect of possible preferred orientation.

\subsection{Phase solubility studies}

The phase solubility study of NCS with HP- $\beta-C D$ was performed following the Higuchi-Connors method [33]. $2 \mathrm{~mL}$ samples containing solutions at various concentrations of HP- $\beta-C D$ were prepared, covering a concentration range from 0.0023 to $0.26 \mathrm{M}$. An excess amount of drug was placed inside each solution, and the resulting suspensions were sonicated for 2 minutes at $37^{\circ} \mathrm{C}$. Subsequently, they were allowed to rest within a thermostatic bath at $37^{\circ} \mathrm{C}$ at a constant oscillation for $48 \mathrm{~h}$. After reaching equilibrium, the samples were centrifuged at 10,000 rpm for $15 \mathrm{~min}$ and the surnatante filtered through $0.45 \mu \mathrm{m}$ cellulose 
acetate (CA) membrane filters was analyzed. The concentration of NCS was assessed by UV at a wavelength of $340 \mathrm{~nm}$ after 1/10 dilutions in ethanol, previous development of the NCS calibration line. The solubility diagram was obtained by plotting the drug molar concentration against the HP- $\beta$-CD molar concentration. Calculation of the complexation constant $\left(\mathrm{Kc}_{1: 1}\right)$ was performed using Eq. (1) [33]:

$$
K C 1: 1=\frac{P}{S_{0}(1-P)}
$$

where:

$S_{0}=$ Intrinsic solubility of NCS in water.

$\mathrm{P}=$ Slope of the phase solubility diagram.

Moreover, the phase solubility study was carried out in the presence of $C D$ (different concentrations from $0.00325 \mathrm{M}$ to $0.026 \mathrm{M}$ ) and $40 \% \mathrm{w} / \mathrm{w}$ HMPC (same HP- $\beta-\mathrm{CD} / \mathrm{HPMC}$ ratio in blends 3 and 4 ), in order to assess whether the formation of a ternary polymeric system could generate a further increase in drug solubility. The same procedure as described above was performed.

\subsection{Homogeneity of HME filaments}

Before the printing stage, preliminary studies were performed to evaluate the behavior of the four blends during extrusion as well as the characteristics of the extruded filament. In the present study, the 3DForMe ${ }^{\circledR}$ pharmaceutical 3D printer (Farmalabor srl, Canosa di Puglia, ITALY) was used (Fig. 1), consisting of a loading hopper, a single-screw extruder and temperature sensing and control systems. $2 \mathrm{~g}$ of each blend were placed in the hopper and the formation of the filament by the extrusion was operated at $180^{\circ} \mathrm{C}$. At the end of each extrusion the filaments were weighed to calculate the yield of the process. Then, from each generated filament, 5-8 pieces of $2 \mathrm{~cm}$ length were cut, exactly weighted, and studied to demonstrate the homogeneity of the filaments printed. In particular, visual inspection and amount of NCS were considered. The pieces were dissolved in $4 \mathrm{~mL}$ of ethanol by stirring overnight. After appropriate dilution, the solutions were analyzed by UV to calculate di amount of NCS in each piece.

\subsection{Direct Powder Extrusion 3D-printing}

The tablets were printed using 3DForMe® pharmaceutical 3D printer (Farmalabor srl, Canosa di Puglia, ITALY), which is specifically designed for pharmaceutical manufacturing (Fig. 1). The model of the tablets was created using the CAD software Fusion360, which allowed the creation of stereolithography (.stl) files that were subsequently exported to the 3D printer software (Ultimaker Cura). The stereolithography file describes the geometry of the object, while all other parameters are set directly in the Ultimaker Cura software. A cylindrical geometry was selected for the tablet 3D printing with dimensions of $12 \mathrm{~mm}$ diameter $\times 3.7 \mathrm{~mm}$ height. This size made it possible to obtain tablets of the required weight, $500 \mathrm{mg}$. The parameters set in the software for printing were: Infill $70 \%$ with Infill pattern Concentric, Top and Bottom Pattern Zig-Zag, High resolution with brim, without raft, Travel speed $5 \mathrm{~mm} / \mathrm{s}$, 
Print speed $5 \mathrm{~mm} / \mathrm{s}$, Number of shells 2, Layer height $0.2 \mathrm{~mm}$, Floor temperature $70^{\circ} \mathrm{C}$, and extrusion temperature of $180^{\circ} \mathrm{C}$. The prepared powder mixture was added to the extruder hopper of the 3D printer, which used was specifically designed with a direct single-screw powder extruder and a nozzle diameter of $0.8 \mathrm{~mm}$. The extruder design is based on a single screw HME and the rotation speed was controlled by the 3D printer software. Furthermore, the extruder nozzle moves in three dimensions to create the objects in a layer-by-layer texture. During printing, all blends met the same extrusion temperature conditions set in the software. At the end of each formulation printing, the extruder is disassembled and removed from the screw, which is cleaned to avoid contamination between the blends studied.

Figure 1 Design of the nozzle of the direct single-screw powder extruder 3D printer.

\subsection{Characterization of printed tablets}

The physical dimensions of the printed tablets were assessed by a digital slide gauge Hitech Diamond. The morphology of the tablets obtained at the printing stage was evaluated by electrical scanning microscopy (SEM), operating at 20 kV (Hitachi TM 3000 Tabletop SEM). Furthermore, a Chemical Microanalysis test was conducted on the four tablets to confirm the presence of $\mathrm{N}$ and $\mathrm{Cl}$, elements present only in the NCS structure, and thus investigate the dispersion of the drug within them. The surface of each printed tablets was analyzed using Swift ED3000 Oxford Instrument with AZtecOne software. The breaking strength of 10 tablets of each formulation type was evaluated using a conventional Erweka GmbH D-63150 durometer. Then, an increasing force was applied to each tablet perpendicular to the plane until a fracture was formed on the tablet surface, thus indicating the total breaking force value relative to the individual tablet. Finally, 10 tablets of each formulation were dissolved in ethanol to evaluate the actual loading of NCS. In detail, each tablet was placed in $100 \mathrm{~mL}$ of ethanol and stirred overnight at room temperature. Finally, after appropriate dilution, the drug concentration was assessed by UV as above reported.

\subsection{Solid state characterization of tablets}

Tablets were characterized by FT-IR, DSC, and PXRD, following the same procedures previously described for solid-state characterization of the blends. Before analysis, the different printed tablets were fragmented, ground, and sieved.

\subsection{Dissolution testing}

The dissolution profiles of the NCS loaded in the tablets were studied for 48 hours using the VK 7000 paddle dissolver. Tablets were placed in vessels containing $900 \mathrm{~mL}$ of simulated gastric fluid $(0.2 \% \mathrm{~W} / \mathrm{v}$ $\mathrm{NaCl}$ and $2 \% \mathrm{w} / \mathrm{v}$ Tween 80 in $0.1 \mathrm{~N} \mathrm{HCl}, \mathrm{pH} 1.2$ ) for the first 2 hours. For the subsequent hours, analysis was performed by placing the sample in $900 \mathrm{~mL}$ of simulated enteric fluid $(2 \% \mathrm{w} / \mathrm{v}$ Tween 80 in Phosphate Buffer pH 6.8, F. U. I. XII [34]). Dissolution was performed at $37^{\circ} \mathrm{C}$ under paddle stirring (100 $\mathrm{rpm})$. NCS quantitative evaluation was conducted by taking hourly $5 \mathrm{~mL}$ samples from the solution and assessing the concentration of NCS dissolved by UV. 
The samples were stored in a Climacell 222 - ECO line climatic chamber (MMM Group, Semmelweis Strasse, München, Germany) at $25^{\circ} \mathrm{C}$ and $60 \%$ relative humidity (RH) for 3 months. The printed tablets were packaged in amber glass bottles and closed with plastic screw caps. They were monitored by DSC analysis and content of NCS over the period of storage.

\subsection{Statistical analysis}

The experimental data were reported as mean \pm SD (standard deviation). Statistical analysis was conducted by Graph Prism version 6.0 (Graphad Sofware Inc., La Jolla, CA, USA).

\section{Results And Discussion}

This work presented and used for the first time a new pharmaceutical 3D printer, 3DForMe ${ }^{\circledR}$, which is based on the ability to extrude powders directly, thus overcoming the filament preparation limits associated with FDM. Different blends consisting of NCS and various concentrations of HPMC, HP- $\beta-C D$ and PEG 6000 were first characterized and then extruded as such through 3DForMe ${ }^{\circledR}$, obtaining sustained release tablets. A complete solid-state characterization of the different blends and tablets achieved has been described, together with in vitro dissolution studies of the 3D printed tablets.

\subsection{NCS Phase solubility studies}

Phase solubility studies of the drug in the presence of HP- $\beta-C D$ were performed, allowing the evaluation of the stability constant and to foresee the stoichiometric ratio of the NCS-HP- $\beta$-CD complex. Pure NCS has an intrinsic solubility of $8 \mu \mathrm{g} / \mathrm{mL}$ in water. The phase solubility plot displays a significant and linear increase in NCS solubility with increasing HP- $\beta-C D$ concentration (Fig. 2). The drug shows a solubility of $54.46 \mu \mathrm{g} / \mathrm{mL}$ in the presence of HP- $\beta-C D$ at a concentration of $0.26 \mathrm{M}$. The regression analysis $\left(\mathrm{R}^{2}=\right.$ 0.9846) describes an AL-type curve, according to the Higuchi-Connors classification, with a slope of less than 1, which could be associated with a 1:1 molar ratio between NCS and HP- $\beta-C D$. By Higuchi Connnors equation was calculated the constant stability equal to $876.1 \mathrm{M}^{-1}$ indicating a good interaction between NCS and HP- $\beta-C D$. Indeed, in leterature stability constant values between $50-2000 \mathrm{M}^{-1}$ are regarded favourable [35].

Figure 2 Phase solubility diagram. The change in NCS solubility within solutions of increasing HP- $\beta-C D$ concentration (0.0023-0.26 M) was assessed. The analysis was carried out in triplicate.

The addition of HPMC at HP- $\beta-C D$ solution significantly improved the aqueous solubility of NCS, confirming that the use of hydrophilic polymers such as HPMC increased the CD complexation efficiency for drugs [31]. In all samples containing the ternary system (HPMC/HP- $\beta$-CD/NCS), a 10-fold increase in aqueous solubility of NCS was observed in comparison to solution containing the HP- $\beta$-CD (Fig. 3). Based on these results, it could be stated that HPMC and HP- $\beta-C D$ showed a synergistic effect in enhancing NCS solubility. 
Figure 3 Aqueous solubility of NCS in the presence of binary (CD/NSC) and ternary (CD/NCS/HPMC) polymeric systems at different HP- $\beta-C D$ concentrations. The analysis was conducted in triplicate.

\subsection{Visual inspection and Homogeneity of HME filaments}

The filaments share some common characteristics, even though they are derived from different powder blends. In fact, all four filaments show a color variation during extrusion: the filament at the beginning of the extrusion has a very dark color that tends to lighten at the end of the process (Fig. 4). The four filaments had a smooth surface and were not brittle at handling.

Figure 4 Fragments derived from a single filament: A) Filament 1; B) Filament 2; C) Filament 3; D) Filament 4.

The yield of the extrusion process was very high, considering that almost all the powder in the hopper was completely extruded and that the weight of the entire filament coincided with the weight of the blend from which it was obtained.

Each piece of filaments, cut in equal length, had a similar weight and although the change in color of the extruded filament might suggest degradation or a change in the stability of the drug, which often occurred during the HME process, the NCS present within the entire filament obtained with the DPE technique retained its stability (see Table 2). Indeed, respecting the correct extrusion order, the single pieces were analyzed to assess the concentration of NCS present in them. The study of filament homogeneity shows that in the four filaments there are fragments in which the drug is under-extruded, which are compensated by fragments in which the drug is over-extruded (Fig. 5). For all the filaments, the values of the percentage of drug are in the range between 6.34 and $13.57(\% \mathrm{w} / \mathrm{w})$. However, the average of the values obtained is very close to the value of the theoretical concentration, thus demonstrating that the adopted process was not detrimental for the drug (Table 2) despite the contact with the high temperatures of the extruder.

Figure 5 Homogeneity study of HME filaments. The graph shows the concentration (\%p/p) of NCS as a function of the measuring points. Each point corresponds to the fragment obtained from the filament in accordance with the extrusion order. The analysis was carried out in triplicate. 
Table 2

Average of NCS concentrations (\%) present within the four different HME filaments.

\begin{tabular}{|lll|}
\hline Filament & Theoretical NCS (\% w/w) & Measured NCS (\% w/w) * \\
\hline $\mathbf{1}$ & 10 & $9.81 \pm 1.72$ \\
\hline $\mathbf{2}$ & 10 & $9.87 \pm 1.36$ \\
\hline $\mathbf{3}$ & 10 & $9.61 \pm 2.30$ \\
\hline $\mathbf{4}$ & 10 & $9.68 \pm 1.32$ \\
\hline * The value is the average of 8 fragments. \pm is the deviation standard. \\
\hline
\end{tabular}

The single screw extruder printer model was used for the first time to enable DPE. The blend powder realized was inserted in the hopper, heated to a specific temperature, and used for direct tablet printing. This innovative printing technique overcomes the limitations associated not only with conventional tablet printing systems [19], but also with established printing processes such as HME. The elimination of the preliminary HME step followed by FDM printing makes the DPE printing process much simpler and faster. In fact, the overall process of printing one tablet takes 13 minutes. In addition, with no intermediate steps, the amount of raw material waste is also greatly reduced. The design of the extruder with a vertical orientation and its adequate distance from the hopper facilitate the flow of powder into the screw. A functional amount of powder can be placed inside the hopper to ensure a production from 1 to 15 tablets for cycle. This makes the 3D printer suitable for formulating personalized medicine often required with galenic preparations.

All powder blends were found to be suitable for DPE 3DP. Only the extrusion of powder blend 3 led to the formation of final tablets considered unsatisfying. Different temperatures and printing parameters (screw speed) were tested in order to improve the characteristics, but none of the modifications improved the printing quality. A possible cause may be attributable to the presence of cyclodextrin, which tended to moisten the powder as the residence time in the printer increased, creating vacuum zones along the screw, and leading to extruder blockage. This problem did not occur during the filament extrusion phase due to the reduced time the powder spent in contact with the extruder. This demonstrates that the DPE process requires powders with a certain degree of fluidity and homogeneity to ensure an uniform flow through the extruder [36]. Blend 3 was then modified by adding $2 \%$ silica and $1 \%$ talc, as dehydrating and glidant agents respectively, which allowed printing without any problems. It should be noted that Blend 4 also consisted of a percentage of HP- $\beta-C D$; however, the presence of the plasticizer and glidant agent (PEG 6000) helped the printed process, favoring the powder to flow within the screw. The resulting NCS printed tablets showed a cylindrical shape and good adhesion between the printed layers (Fig. 6).

Figure 6 From left to right: Tablet 1, Tablet 2, Tablet 3 and Tablet 4 derived from the extrusion of Blend 1, 2,3 and 4 respectively. 


\subsection{Characterization of tablets}

Tablets exhibited good uniformity in physical dimensions, with diameter and height values deviating slightly from the respective values set on the digital model $(12 \mathrm{~mm} \times 3.7 \mathrm{~mm})$. The mean diameter ranged from $11.88 \mathrm{~mm}$ to $12.50 \mathrm{~mm}$, and the mean height ranged from $3.12 \mathrm{~mm}$ to $3.92 \mathrm{~mm}$. The mean mass was described by values ranging from 436.50 to $504.67 \mathrm{mg}$. This variation could be due to the different composition of the individual blends, which gives the powders different flow properties in the extruder. All tablets had mechanical properties that are functional for packaging and handling. The required breaking strength of the tablets has values above $100 \mathrm{~N}$ up to the maximum value that can be measured with the durometer, $484 \mathrm{~N}$. From the content uniformity test, the drug concentration present in 10 tablets of each formulation was obtained, confirming the closeness to the theoretical drug value, and demonstrating no degradation of the drug during extrusion. All the data described are shown in Table 3.

Table 3

Characteristics of tablets printed by DPE.

\begin{tabular}{|llllll|}
\hline Tablet & $\begin{array}{l}\text { Diameter }(\mathrm{nm}) \\
*\end{array}$ & $\begin{array}{l}\text { Height }(\mathrm{nm}) \\
*\end{array}$ & Weight $(\mathrm{mg}) *$ & $\begin{array}{l}\text { Breaking Force } \\
(\mathrm{N})^{*}\end{array}$ & $\begin{array}{c}\text { NCS Loading (\%) } \\
*\end{array}$ \\
\hline $\mathbf{1}$ & $11.88 \pm 0.25$ & $3.86 \pm 0.28$ & $\begin{array}{l}443.14 \pm \\
59.15\end{array}$ & $453.28 \pm 43.74$ & $9,86 \pm 1.67$ \\
\hline $\mathbf{2}$ & $12.13 \pm 0.30$ & $3.92 \pm 0.11$ & $\begin{array}{l}504.67 \pm \\
21.51\end{array}$ & $484.00 \pm 0.00$ & $9,94 \pm 0.20$ \\
\hline 4 & $12.50 \pm 0.42$ & $3.46 \pm 0.10$ & $\begin{array}{l}482.83 \pm \\
37.44\end{array}$ & $330.67 \pm 109.07$ & $10.40 \pm 0.30$ \\
\hline & $12.47 \pm 0.25$ & $3.12 \pm 0.12$ & $\begin{array}{l}436.50 \pm \\
40.67\end{array}$ & $190.83 \pm 66.84$ & $10.30 \pm 0.38$ \\
\hline
\end{tabular}

Figure 7 SEM images of the cross-section (top in figures) and surface (bottom left in figures) and surface chemical microanalysis (bottom right in figures) of the samples: Tablet 1 (A), Tablet 2 (B), Tablet 3 (C), and Tablet 4 (D).

SEM images show the surface and transverse planes of the four different tablets obtained (Figure 7). Although the tablets were derived from blends consisting of different excipients at various concentration, they are morphologically similar. In the cross-section, the three-dimensional layer-by-layer structure, characteristic of tablets obtained by 3D printing, can be seen. Each layer has a thickness of $0.2 \mathrm{~mm}$, as determined by the printing parameters. The surface plane shows the concentric geometry of the chosen infill.

The data obtained from the chemical microanalysis show a homogeneous presence of the elements $\mathrm{N}$ (green in Fig. 7) and $\mathrm{Cl}$ (red in Fig. 7), which, being atoms exclusively present in the structure of the drug, indicate an equal distribution of NCS within the printed tablets. 


\subsection{Solid state characterization of printed tablets}

The possible amorphization process undergone by the drug during extrusion was verified by solid-state characterization studies of the printed tablets. Using FT-IR it was observed that characteristic peaks in the NCS spectrum were present at 1218, 1520, 1570 and $1650 \mathrm{~cm}^{-1}$ (Fig. 8). The presence of these peaks was confirmed in the medicated blend spectrum for each formulation. Peaks around $3300 \mathrm{~cm}^{-1}$ are characteristic of HP- $\beta-C D$ as seen in the blends and medicated blends (Fig. $8 C-D$ ). From the analysis of the spectrum relative to the tablets obtained from the above blends we can see a relative widening of the HP- $\beta-C D$ peak in a range between 3350 and $3100 \mathrm{~cm}^{-1}$. This widening could be reasonably attributed to the interaction of HP- $\beta-C D$ with HPMC and NCS during the printing step [26]. The same observation can be made regarding the NCS peaks between $1600 \mathrm{~cm}^{-1}$ and $1800 \mathrm{~cm}^{-1}$ and between $1250 \mathrm{~cm}^{-1}$ and 1100 $\mathrm{cm}^{-1}$. The absence of important peaks characteristic of $\mathrm{NH}$ stretching and the stretching of the carbonyl group of the drug could suggest the possible amorphization of the drug inside the printed tablets and/or the interaction between the drug and the HP- $\beta-C D$ [4]. These results could confirm the formation of intimate complexes of HP- $\beta-C D, N C S$ and HPMC.

Figure 8 FT-IR spectra of printed tablets 1 (A), 2 (B), 3 (C), 4 (D), each compared with the spectra of the NCS and the respective blends with (medicated blend) and without drug (blend).

A second test to verify this condition was performed by DSC. NCS shows a strong endothermic peak at $230^{\circ} \mathrm{C}$, descriptive of its crystalline nature (Fig. 9). A smaller endothermic peak is present in the thermogram of the physical blend with the drug (Blend medicated). In contrast, the peak at $230^{\circ} \mathrm{C}$ is completely absent in the thermogram of the tablet for all formulations, probably due to amorphization of the drug during the printing phase and/or the formation of an inclusion complex between the NCS and HP- $\beta-C D$.

Figure 9 Thermograms of printed tablets 1 (A), 2 (B), 3 (C), 4 (D), each compared with the thermograms of the NCS and the respective blends with (medicated blend) and without drug (blend).

In Fig. 10 the powder diffraction patterns of NCS, blend, blend medicated and tablet, are reported for each compound under investigation. The sharp peaks present in the pure NCS powder diffraction pattern indicate its crystallinity, while their complete disappearance in the patterns of tablets, clearly shows the NCS amorphization during the printing phase. This phenomenon, already pointed out by FT-IR and DSC results is confirmed by the PXRD analysis.

Figure 10 Diffractograms of the printed tablets 1 (A), 2 (B), 3 (C), 4 (D), each compared with the diffractograms of the NCS and the respective blends with (medicated blend) and without drug (blend).

\subsection{Dissolution testing of printed tablets}

Dissolution studies of tablets obtained by direct extrusion of the four blends were performed for 48 hours (Fig. 11). NCS release was studied in simulated gastric fluid for the first two hours and in simulated 
enteric fluid for the remaining hours. All tablets enhanced the dissolution profile of the pure drug, offering further confirmation of the advantage of this technique, which induced the loss of the drug's crystalline network during the printing process. Although at different times, all printed tablets showed a sustained and complete drug release within 48 hours. In fact, HP- $\beta$-CD-containing tablets ( 3 and 4 ) achieved 100\% NCS release in 24 hours. In contrast, tablets 1 and 2 released $65 \%$ and $70 \%$ of NCS at 24 hours, respectively, achieving complete drug release at 48 hours. The different release profile of the tablets could be related to the different concentration of HPMC that constitutes them. In fact, the HPMC interacting with the aqueous fluid led to the formation of a gel layer, which acts as a diffusion barrier that counteracted drug release [37]. The thickness of this layer may depend on the concentration of the polymer, in tablets 1 and 2 was present in higher concentrations than tablets containing HP- $\beta-C D$, causing a NCS release slower, but within 48 hours. The high hydrophilicity of HP- $\beta-C D$ and the ability of HPMC to stabilize the NCS/HP- $\beta$-CD complex in solution $[26,31]$ justify the improved release profile obtained from tablets 3 and 4 . Plotting the data of cumulative releases $v s$. time, for the first $8 \mathrm{~h}$, obtained straight lines with R2 $\mathrm{Q} 0.96$ for all tablets, suggesting that the release profiles follow kinetics of order 0 .

The results obtained confirm the amorphization of the drug and the formation of a ternary inclusion complex between HP- $\beta-C D, H P M C$ and NCS, inducing an improvement on drug loading and release.

Figure 11 Dissolution profiles in gastric $(2 \mathrm{~h})$ and enteric $(46 \mathrm{~h})$ fluid of Medicated Tablets.

\subsection{Stability Studies}

The amorphous condition of the drug, initially acquired by the printing process, is checked after 3 months in controlled storage parameters $\left(25^{\circ} \mathrm{C}, 60 \% \mathrm{RH}\right)$, showing no changes in the solid state of the compounds and the drug content, thus indicating the 3-month stability of the tablets obtained (Fig. 9).

\section{Conclusions}

Preparation of tablets containing NCS, HPMC and HP- $\beta$-CD by single-screw DPE 3DP has been proven for the first time. All the printed tablets showed good mechanical and physical features. By means of the in vitro dissolution studies, the results showed for all printed tablets a sustained release of NCS for $48 \mathrm{~h}$, whereas for the tablets containing HP- $\beta-C D$ the release was faster. The solid-state characterization study, using different techniques, revealed the loss of the crystalline state of the drug and a homogeneous distribution of the latter in the polymer matrix. In addition, through a stability study the drug content within the printed tablets was found to be stable for up to 3 months. By using this innovative pharmaceutical printer, $3 \mathrm{DF}$ orMe ${ }^{\circledR}$, which allows the direct extrusion of powders, it was possible to generate tablets, overcoming the limitations of fragment production associated with FDM.

\section{Declarations}

Funding: M.I.U.R- Programma Operativo Nazionale 2014-2020; Azione: I.1- Dottorati di ricerca innovativi 2020. This project has been partially funded from the European Union Horizon 2020 research and 
innovation programme under grant agreement No 768775 titled AMable.

Conflict of interests: the author declare that they have no known competing financial interests or personal relationships that could have appeared to influence the work reported in this paper.

Availability of data and material: not applicable

Code availability: not applicable

Authors' contributions: not applicable

Ethics approval: not applicable

Consent to participate: not applicable

Consent for publication: not applicable

\section{References}

[1] World Health Organization, WHO Model List of Essential Medicines, 20th edition, 2017.

[2] Barbosa EJ, Löbenberg R, de Araujo GLB, Bou-Chacra NA. Niclosamide repositioning for treating cancer: Challenges and nano-based drug delivery opportunities. Eur J. Pharm. Biopharm. 2019; 141:5869. https://doi.org/10.1016/j.ejpb.2019.05.004.

[3] He XG, Li M, Ye WC, Zhou W. Discovery of degradable niclosamide derivatives able to specially inhibit small cell lung cancer (SCLC). Bioorg. Chem. 2021; 107: 104574.

https://doi.org/10.1016/j.bioorg.2020.104574.

[4] Lodagekar A, Borkar R, Thatikonda S, Chavan R, Naidu VGM, Shastri N, Srinivas R, Chella N.

Formulation and evaluation of cyclodextrin complexes for improved anticancer activity of repurposed drug: Niclosamide. Carbohydr. Polym. 2019; 212: 252-259.

https://doi.org/10.1016/j.carbpol.2019.02.041.

[5] Ye T, Xiong Y, Yan Y, Xia Y, Song X, Liu L, Li D, Wang N, Zhang L, Zhu Y, Zeng J, Wei Y, Yu L. The Anthelmintic Drug Niclosamide Induces Apoptosis, Impairs Metastasis and Reduces Immunosuppressive Cells in Breast Cancer Model. PLoS ONE. 2014; 1: e85887.

https://doi.org/10.1371/journal.pone.0085887.

[6] Sack U, Walther W, Scudiero D, Selby M, Kobelt D, Lemm M, Fichtner I, Schlag PM, Shoemaker RH, Stein U. Novel Effect of Antihelminthic Niclosamide on S100A4-Mediated Metastatic Progression in Colon Cancer. J. Nat/ Cancer Inst. 2011;103 (13): 1018-1036. https://doi.org/10.1093/jnci/djr190.

[7] Reagan-Shaw S, Nihal M, Ahmad N. Dose translation from animal to human studies revisited. FASEB J. 2008; 22(3):659-661. https://doi.org/10.1096/fj.07-9574LSF. 
[8] Li R, You S, Hu ZL, Chen ZG, Sica GL, Khuri FR, Curran WJ, Shin DM, Deng X. Inhibition of STAT3 by niclosamide synergizes with erlotinib against head and neck cancer. PloS One. 2013;8: e74670-e70. https://doi.org/10.1371/journal.pone.0074670.

[9] Ren XM, Duan L, He Q, Zhang Z, Zhou Y, Wu D, Pan J, Pei J, Ding K. Identification of Niclosamide as a New Small-Molecule Inhibitor of the STAT3 Signaling Pathway. ACS Med. Chem. Lett. 2010; 1: 454-459. https://doi.org/10.1021/ml100146z.

[10] Cheng PY, Corzo CA, Luetteke N, Yu B, Nagaraj S, Bui MM, Ortiz M, Nacken M, Sorg C, Vogl T, Roth J, Gabrilovich D. Inhibition of dendritic cell differentiation and accumulation of myeloid-derived suppressor cells in cancer is regulated by S100A9 protein. J. Exp. Med. 2008; 205: 2235-2249. https://doi.org/10.1084/jem.20080132.

[11] Chen W, Mook RA, Premont RT, Wang J. Niclosamide: Beyond an antihelminthic drug. Cell. Signal. 2018; 41:89-96. https://doi.org/10.1016/j.cellsig.2017.04.001.

[12] Li Y, Zhang L, Zhang Q, Chen H, Denlinger DL. Host diapause status and host diets augmented with cryoprotectants enhance cold hardiness in the parasitoid Nasonia vitripennis. J. Insect Physiol. 2014; 70: 8-14. https://doi.org/10.1016/j.jinsphys.2014.08.005 .

[13] Tian Y, Jacobs E, Jones DS, McCoy CP, Wu H, Andrews GP. The design and development of high drug loading amorphous solid dispersion for hot-melt extrusion platform. Int. J. Pharm. 2020; 586: 119545. https://doi.org/10.1016/j.ijpharm.2020.119545.

[14] Pandi P, Bulusu R, Kommineni N, Khan W, Singh M. Amorphous solid dispersions: An update for preparation, characterization, mechanism on bioavailability, stability, regulatory considerations and marketed products. Int. J. Pharm. 2020; 586: 119560. https://doi.org/10.1016/j.ijpharm.2020.119560.

[15] Tan D, Maniruzzaman M, Nokhodchi A. Advanced Pharmaceutical Applications of Hot-Melt Extrusion Coupled with Fused Deposition Modelling (FDM) 3D Printing for Personalised Drug Delivery.

Pharmaceutics. 2018; 10: 203. https://doi.org/10.3390/pharmaceutics10040203.

[16] Patil H, Tiwari RV, Repka MA. 2016. Hot-Melt Extrusion: From Theory to Application in Pharmaceutical Formulation. AAPS PharmSciTech. 2016; 17: 20-42. https://doi.org/10.1208/s12249015-0360-7.

[17] Cui M, Pan H, Su Y, Fang D, Qiao S, Ding P, Pan W. Opportunities and challenges of three-dimensional printing technology in pharmaceutical formulation development. Acta Pharm Sin B. 2021; 11: 2488-2504. https://doi.org/10.1016/j.apsb.2021.03.015.

[18] Paul GM, Rezaienia A, Wen P, Condoor S, Parkar N, King W, Korakianitis T. Medical Applications for 3D Printing: Recent Developments. Mo Med. 2018; 115:75-81. 
[19] Pandey M, Choudhury H, Fern JLC et al. 3D printing for oral drug delivery: a new tool to customize drug delivery. Drug Deliv. and Transl. Res.2020; 10: 986-1001. https://doi.org/10.1007/s13346-02000737-0.

[20] Jain KK. Textbook of Personalized Medicine. 2nd ed. Basel, Switzerland: Humana Press; 2009:1-3.

[21] Li YY, Jones SJM. Drug repositioning for personalized medicine. Genome Med. 2012; 4: 27-40. https://doi.org/10.1186/gm326.

[22] Sandler N, Preis M. Printed Drug-Delivery Systems for Improved Patient Treatment. Trends Pharmacol. Sci.2016; 37 (12): 1070-1080. https://doi.org/10.1016/j.tips.2016.10.002.

[23] Zema L, Melocchi A, Maroni A, Gazzaniga A. Three-Dimensional Printing of Medicinal Products and the Challenge of Personalized Therapy. J. Pharm. Sci. 2017;106(7): 1697-1705. https://doi.org/10.1016/j.xphs.2017.03.021.

[24] Goyanes A, Allahham N, Trenfield SJ, Stoyanov E, Gaisford S, Basit AW. 2019. Direct powder extrusion 3D printing: Fabrication of drug products using a novel single-step process. Int. J. Pharm. 2019; 567. https://doi.org/10.1016/j.ijpharm.2019.118471.

[25] Aho J, Bøtker JP, Genina N, Edinger M, Arnfast L, Rantanen J. 2019. Roadmap to 3D-Printed Oral Pharmaceutical Dosage Forms: Feedstock Filament Properties and Characterization for Fused Deposition Modeling. J. Pharm. Sci. 2019; 108(1): 26-35. https://doi.org/10.1016/j.xphs.2018.11.012.

[26] Thiry J, Krier F, Ratwatte S, Thomassin JM, Jerome C, Evrard B. Hot-melt extrusion as a continuous manufacturing process to form ternary cyclodextrin inclusion complexes. Eur. J. Pharm. Sci. 2017; 96: 590-597. https://doi.org/10.1016/j.ejps.2016.09.032.

[27] Elbadawi M, Muñiz Castro B, Gavins FKH, Ong JJ, Gaisford S, Pérez G, Basit AW, Cabalar P, Goyanes A. M3DISEEN: A novel machine learning approach for predicting the 3D printability of medicines. Int $\mathrm{J}$ Pharm. 2020; 590: 119837. doi: 10.1016/j.jpharm.2020.119837.

[28] Loftsson T, Brewster ME. Pharmaceutical applications of cyclodextrins: basic science and product development. J. Pharm. Pharmacol. 2010; 62: 1607-1621. https://doi.org/10.1111/j.20427158.2010.01030.x.

[29] Patel AR, Vavia PR. Preparation and Evaluation of Taste Masked Famotidine Formulation Using Drug/ $\beta$-cyclodextrin/Polymer Ternary Complexation Approach. AAPS PharmSciTech. 2008; 9: 544550. https://doi.org/10.1208/s12249-008-9078-0.

[30] Marreto RN, Cardoso G, dos Santos Souza B, Martin-Pastor M, Cunha-Filho M, Taveira SF, Concheiro A, Alvarez-Lorenzo C. Hot melt-extrusion improves the properties of cyclodextrin-based poly(pseudo)rotaxanes for transdermal formulation. Int. J. Pharm. 2020; 586:

119510. https://doi.org/10.1016/j.ijpharm.2020.119510. 
[31] Medarević D, Kachrimanis K, Djurić Z, Ibrić S. Influence of hydrophilic polymers on the complexation

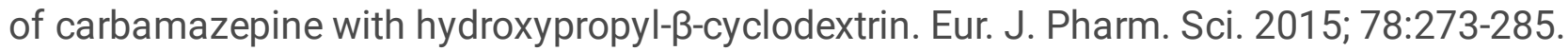
https://doi.org/10.1016/j.ejps.2015.08.001.

[32] Taupitz T, Dressman JB, Buchanan CM, Klein S. Cyclodextrin-water soluble polymer ternary complexes enhance the solubility and dissolution behaviour of poorly soluble drugs. Case example: Itraconazole. Eur J Pharm Biopharm. 2013; 83:378-387. DOI: 10.1016/j.ejpb.2012.11.003.

[33] Higuchi T, Connors KA. Phase Solubility Techniques. Adv. Anal. Chem. Instrum.1965;4:117-212.

[34] Italian Official Pharmacopoeia XII edition: 351-352.

[35] Loftsson T, Hreinsdóttir D, Másson M. Evaluation of cyclodextrin solubilization of drugs. Int. J. Pharm. 2005; 302:18-28. https://doi.org/10.1016/j.ijpharm.2005.05.042.

[36] Spath S, Seitz H. Influence of grain size and grain-size distribution on workability of granules with 3D printing. Int. J. Adv. Manuf. Technol. 2014; 70: 135-144. DOI 10.1007/s00170-013-5210-8.

[37] Palugan L, Filippin I, Cirilli M, Moutaharrik S, Zema L, Cerea M, Maroni A, Foppoli A, Gazzaniga A. Cellulase as an "active" excipient in prolonged-release HPMC matrices: A novel strategy towards zeroorder release kinetics. Int. J. Pharm. 2021; 607:121005. https://doi.org/10.1016/j.ijpharm.2021.121005.

\section{Figures}

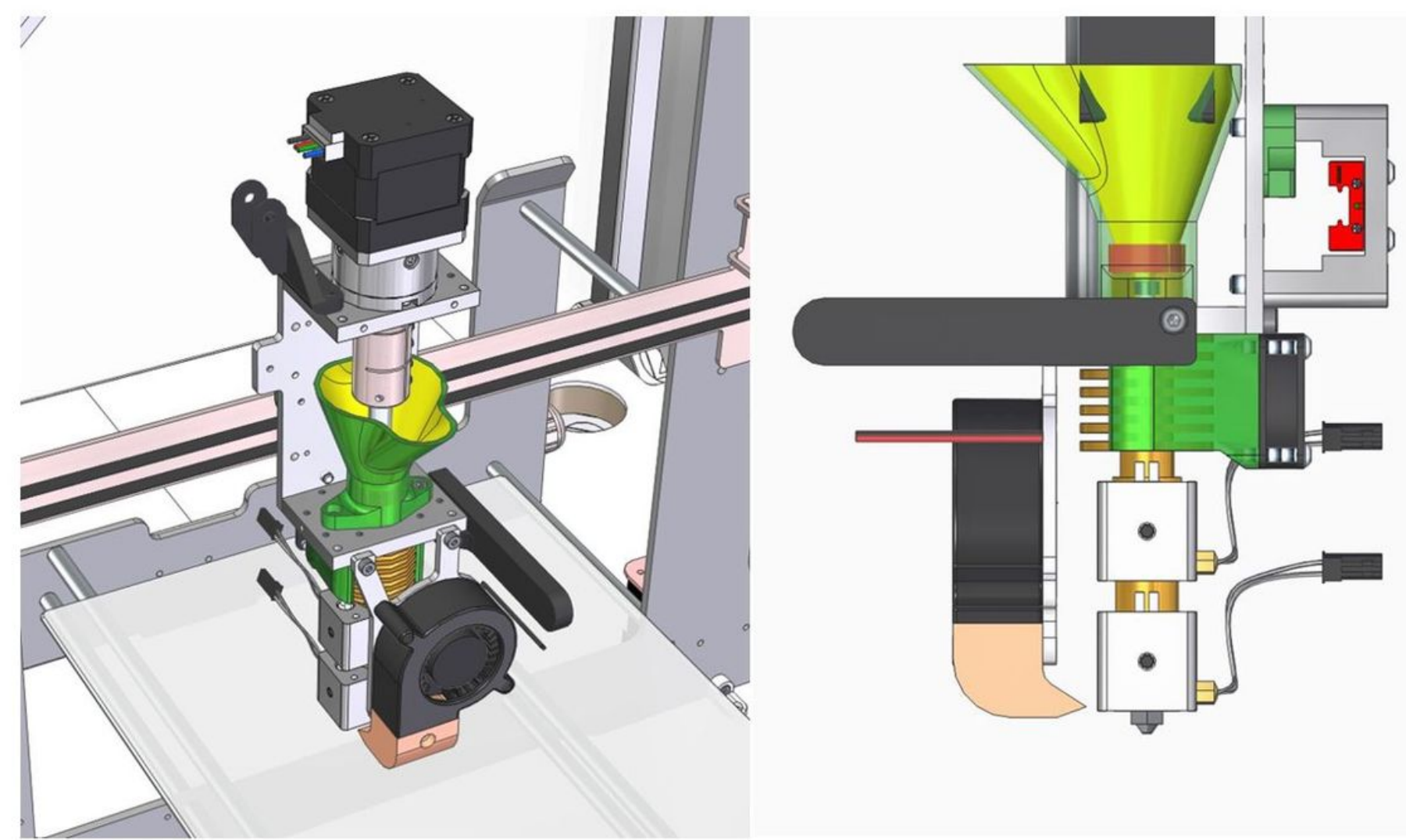


Figure 1

Design of the nozzle of the direct single-screw powder extruder 3D printer.

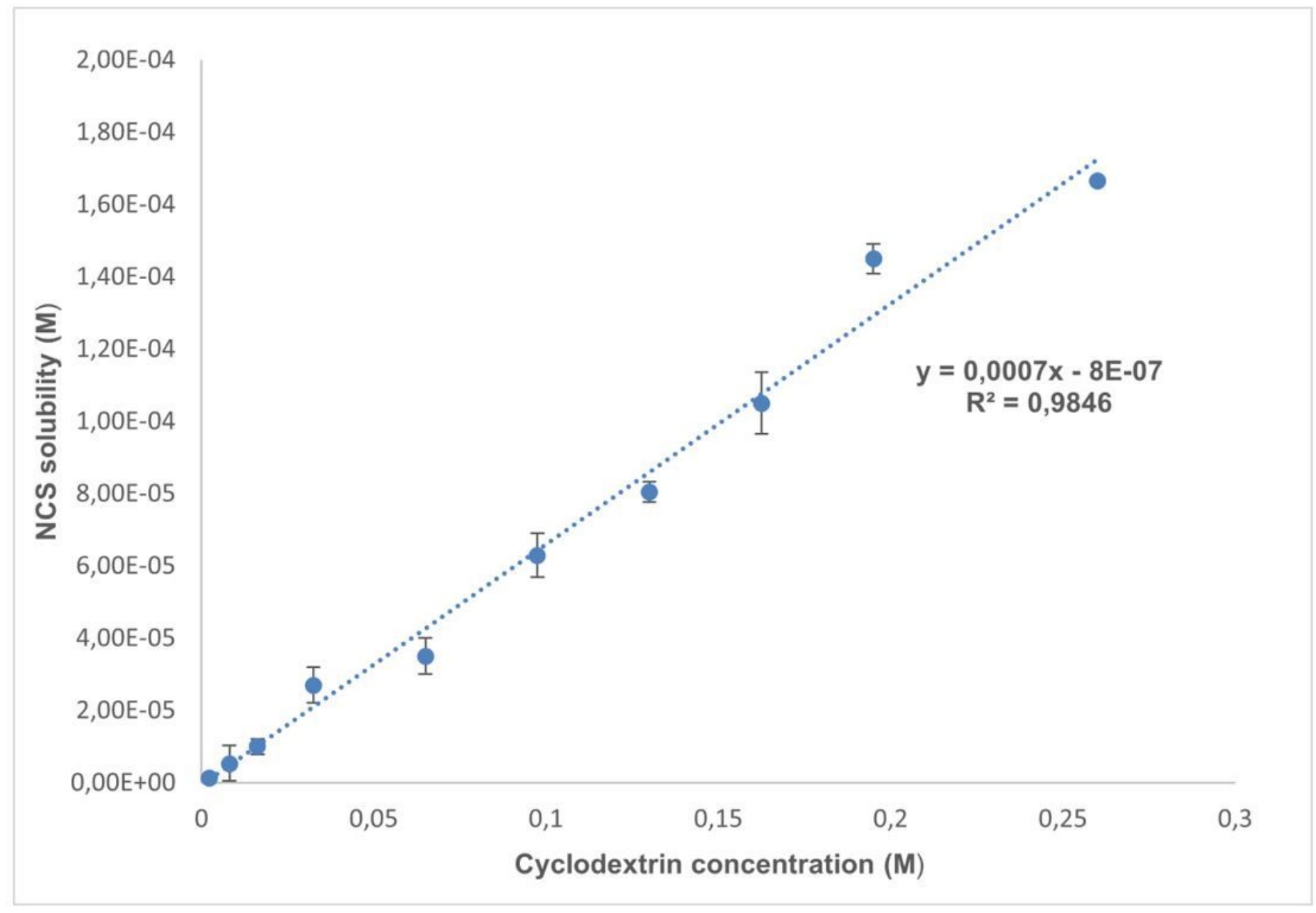

\section{Figure 2}

Phase solubility diagram. The change in NCS solubility within solutions of increasing HP- $\beta-C D$ concentration ( $0.0023-0.26 \mathrm{M})$ was assessed. The analysis was carried out in triplicate. 


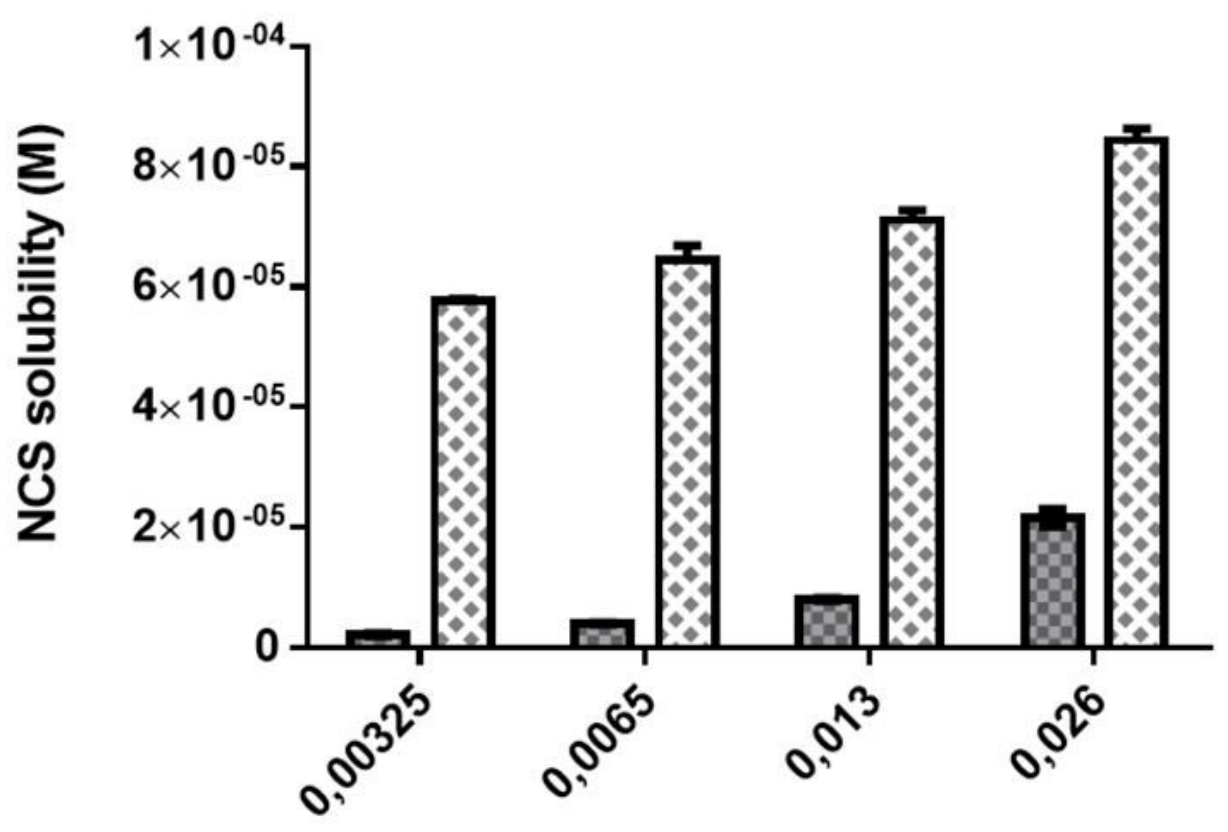

CD/NCS

CD/NCS/HPMC

\section{Cyclodextrin concentration (M)}

Figure 3

Aqueous solubility of NCS in the presence of binary (CD/NSC) and ternary (CD/NCS/HPMC) polymeric systems at different HP- $\beta-C D$ concentrations. The analysis was conducted in triplicate.

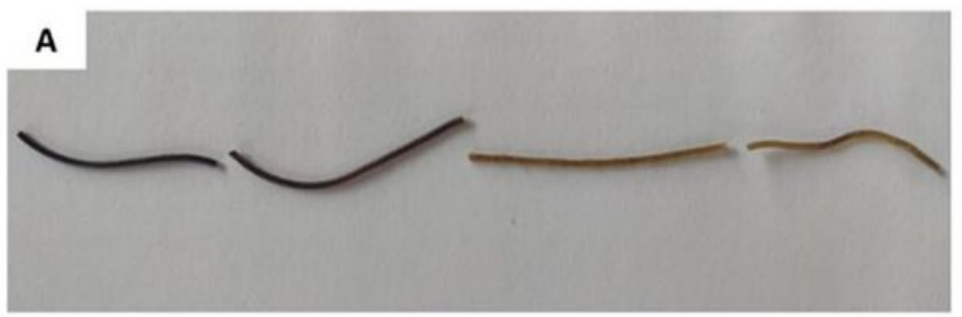

\section{B}

C

D
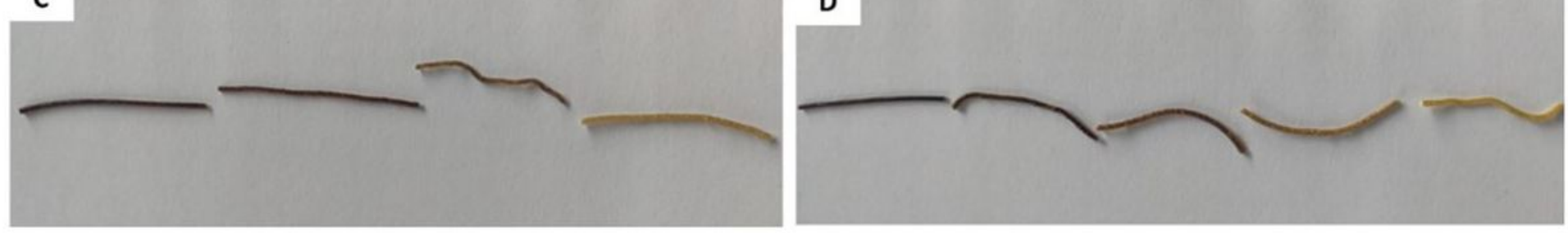

Figure 4

Fragments derived from a single filament: A) Filament 1; B) Filament 2; C) Filament 3; D) Filament 4. 


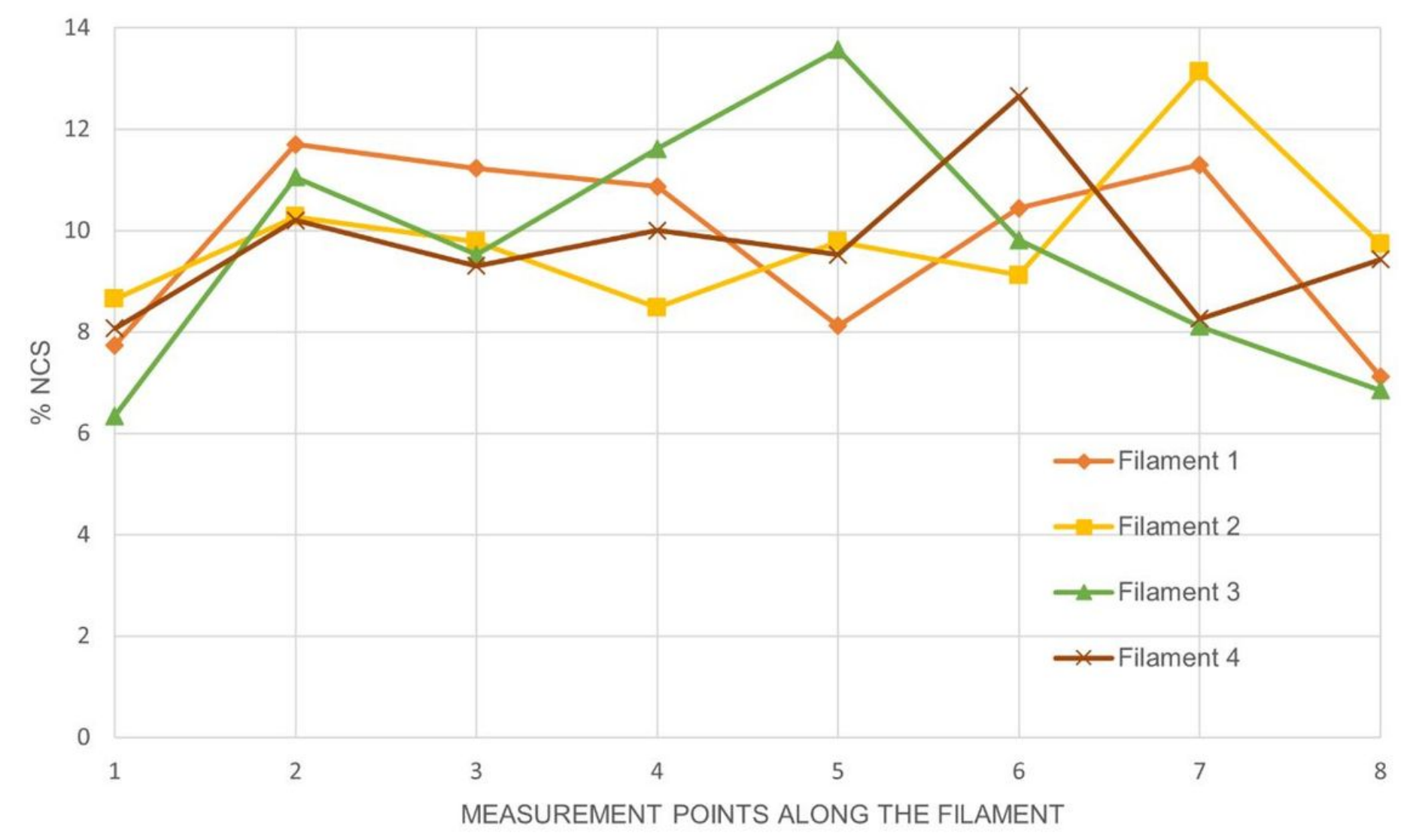

\section{Figure 5}

Homogeneity study of HME filaments. The graph shows the concentration (\%p/p) of NCS as a function of the measuring points. Each point corresponds to the fragment obtained from the filament in accordance with the extrusion order. The analysis was carried out in triplicate.

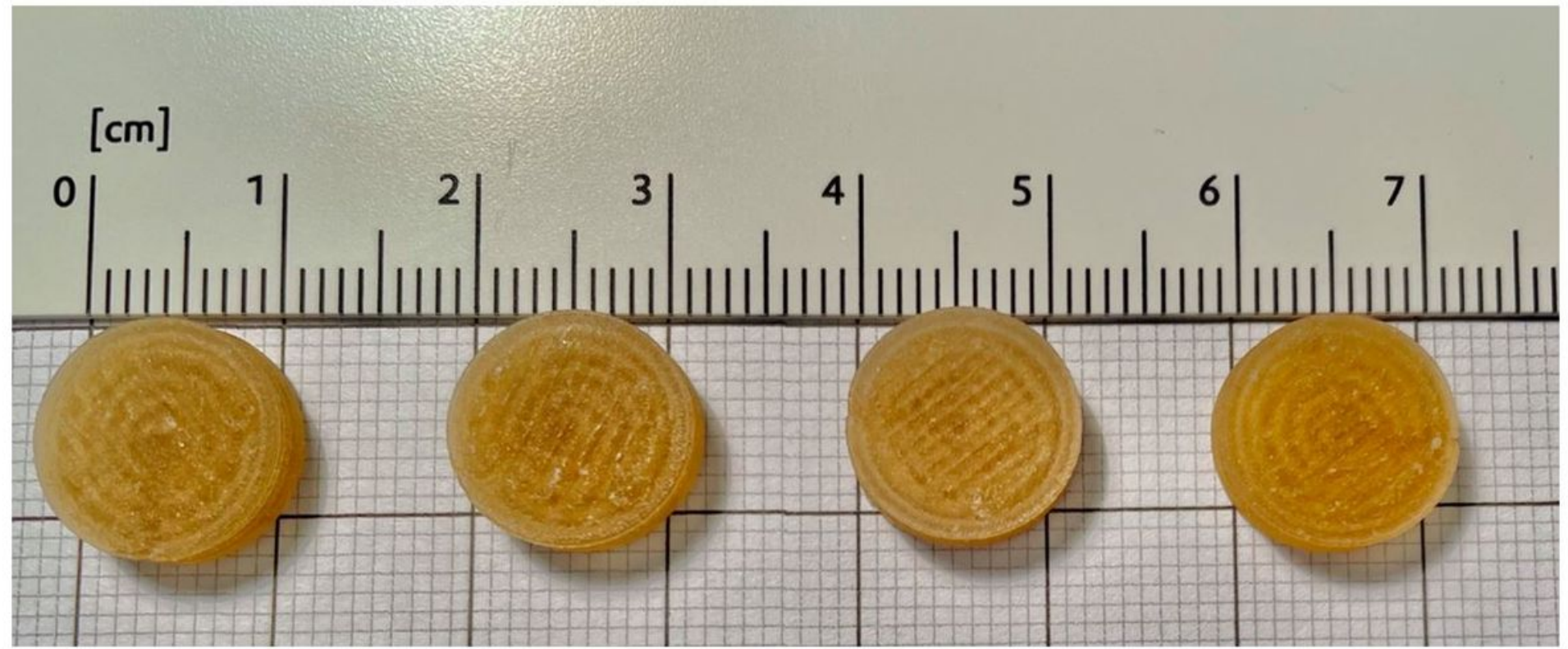




\section{Figure 6}

From left to right: Tablet 1, Tablet 2, Tablet 3 and Tablet 4 derived from the extrusion of Blend 1, 2, 3 and 4 respectively.
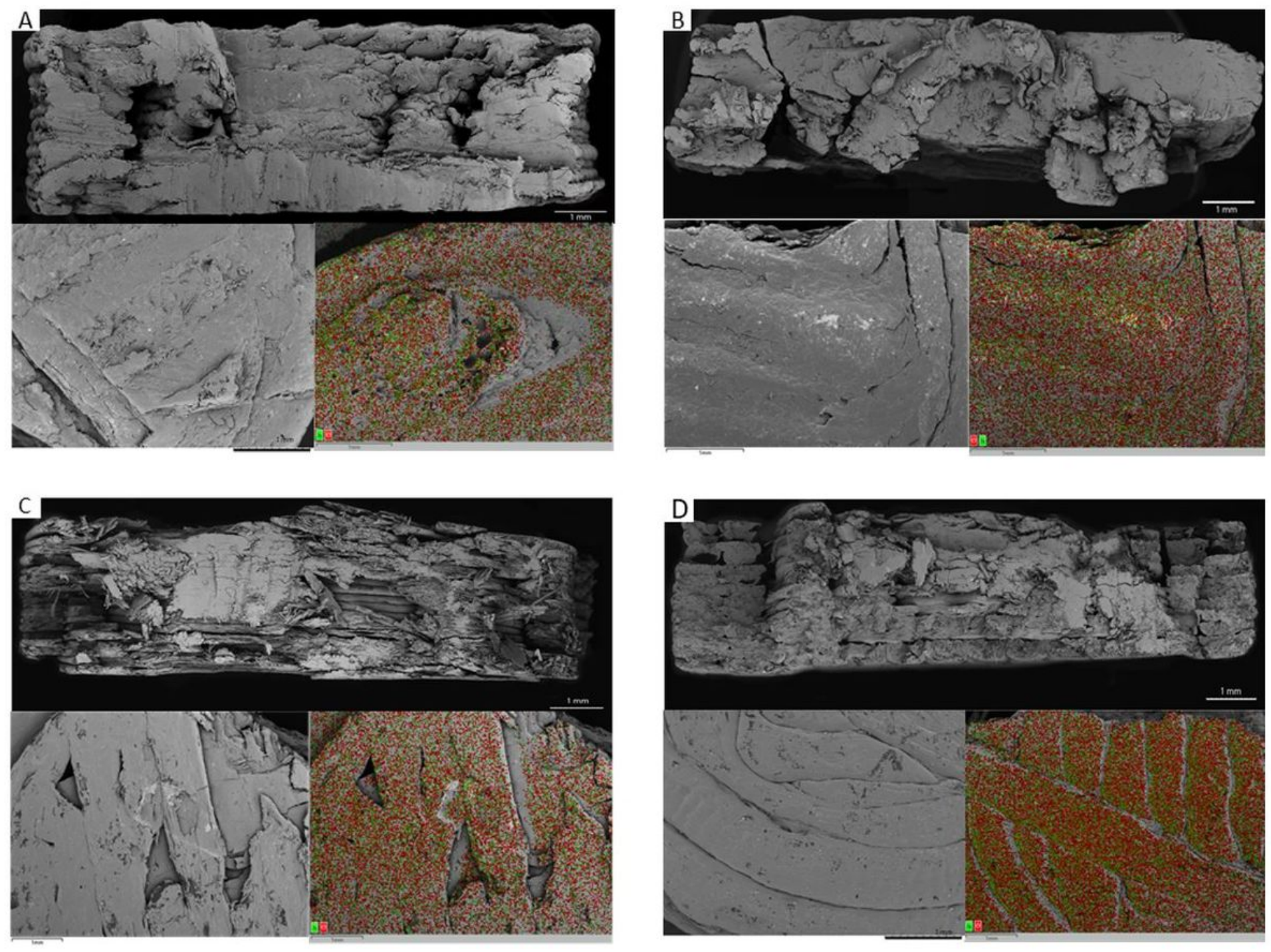

\section{Figure 7}

SEM images of the cross-section (top in figures) and surface (bottom left in figures) and surface chemical microanalysis (bottom right in figures) of the samples: Tablet 1 (A), Tablet 2 (B), Tablet 3 (C), and Tablet 4 (D). 

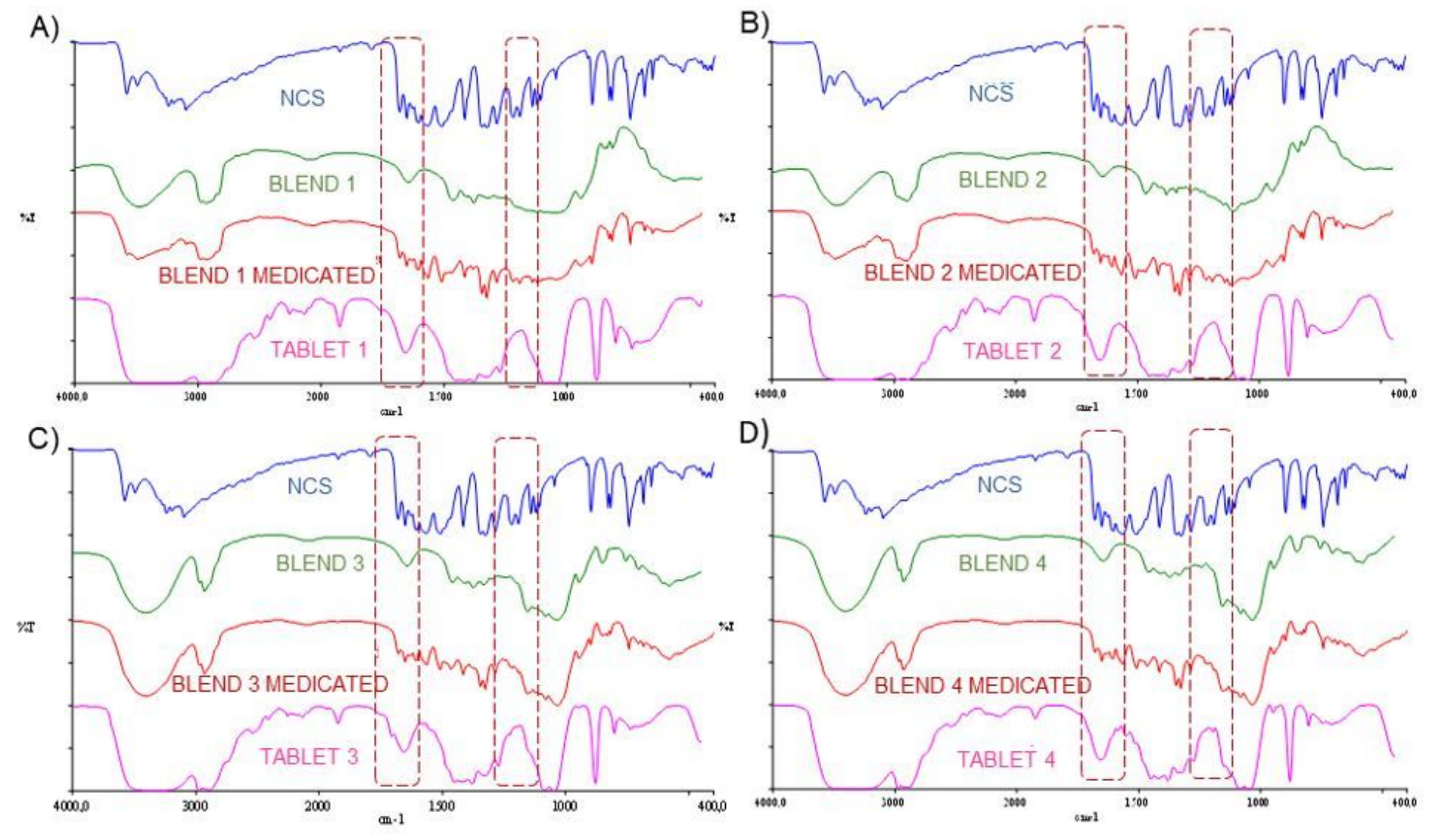

\section{Figure 8}

FT-IR spectra of printed tablets 1 (A), 2 (B), 3 (C), 4 (D), each compared with the spectra of the NCS and the respective blends with (medicated blend) and without drug (blend). 

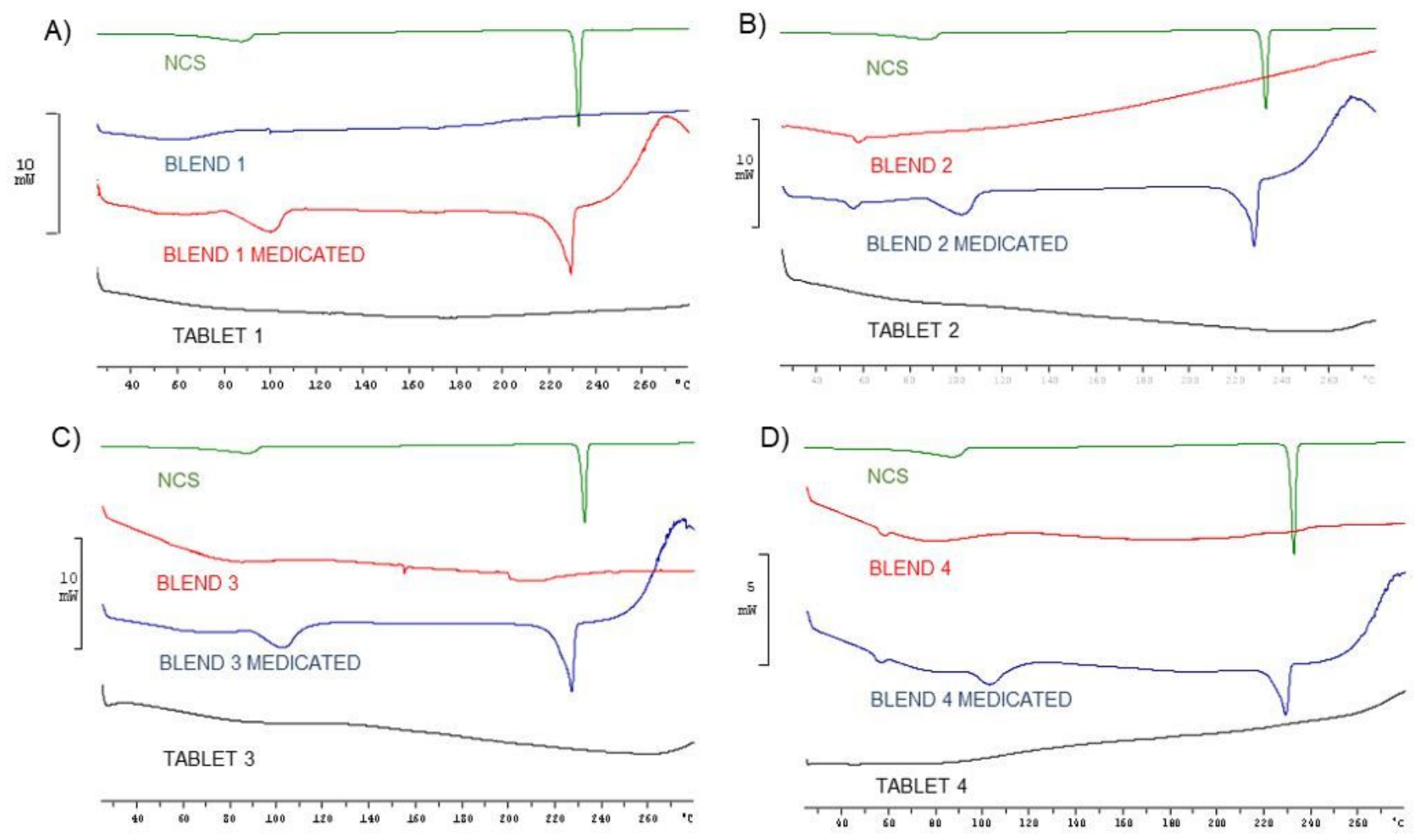

\section{Figure 9}

Thermograms of printed tablets 1 (A), 2 (B), 3 (C), 4 (D), each compared with the thermograms of the NCS and the respective blends with (medicated blend) and without drug (blend). 
A)

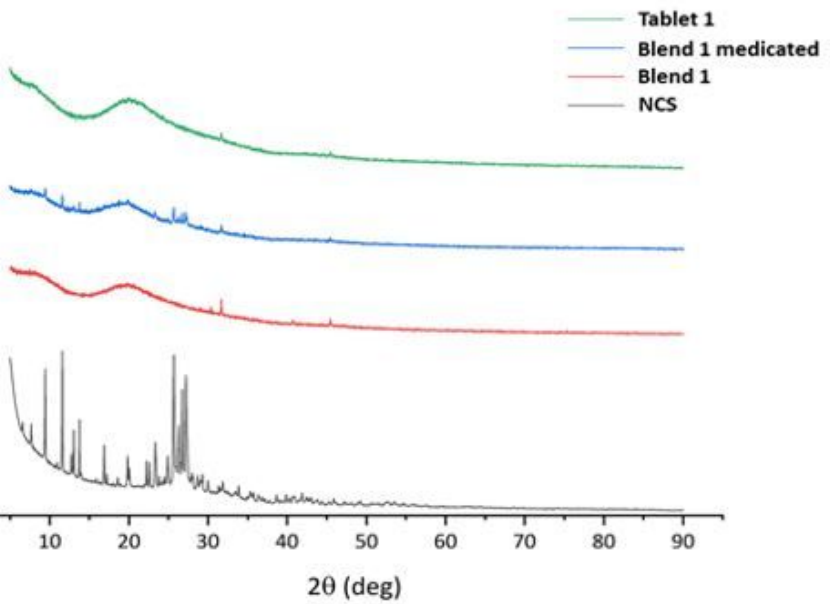

C)

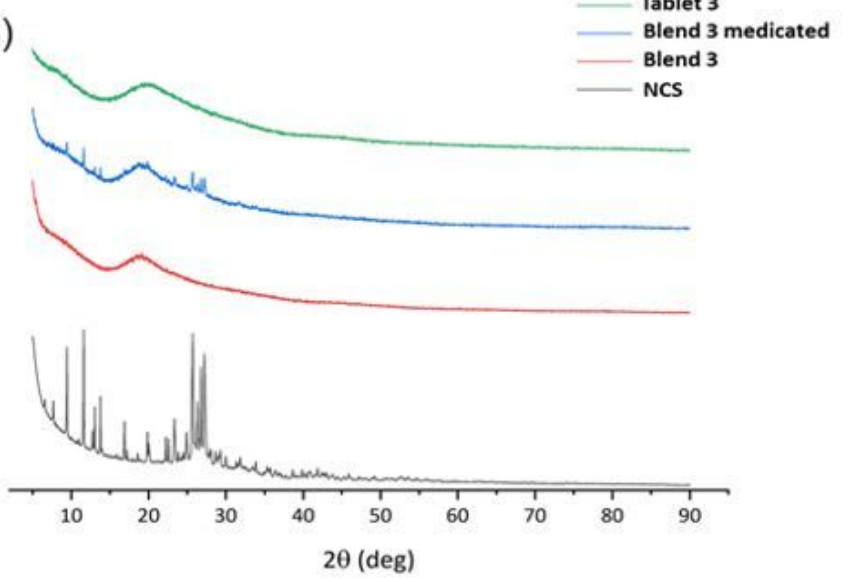

B)
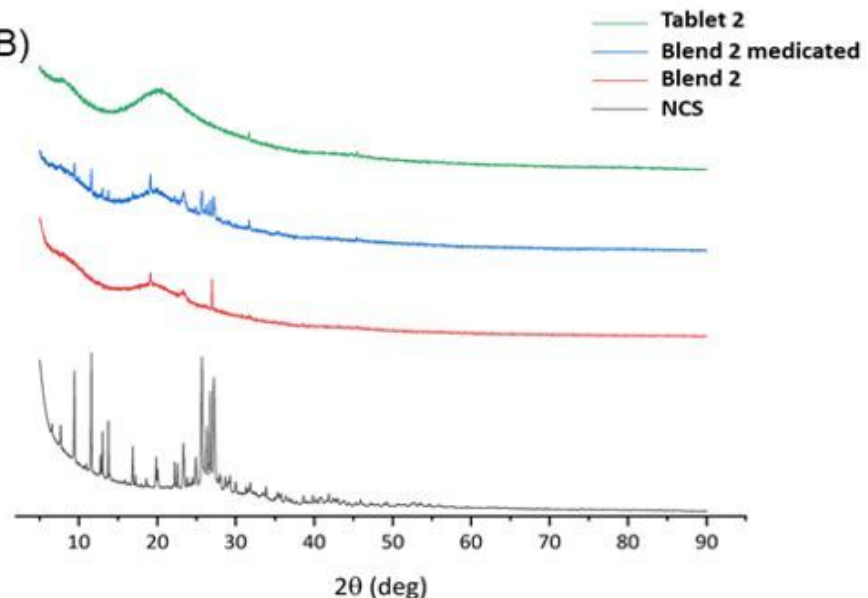

D)

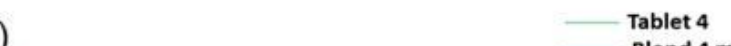

Blend 4 medicated Blend 4

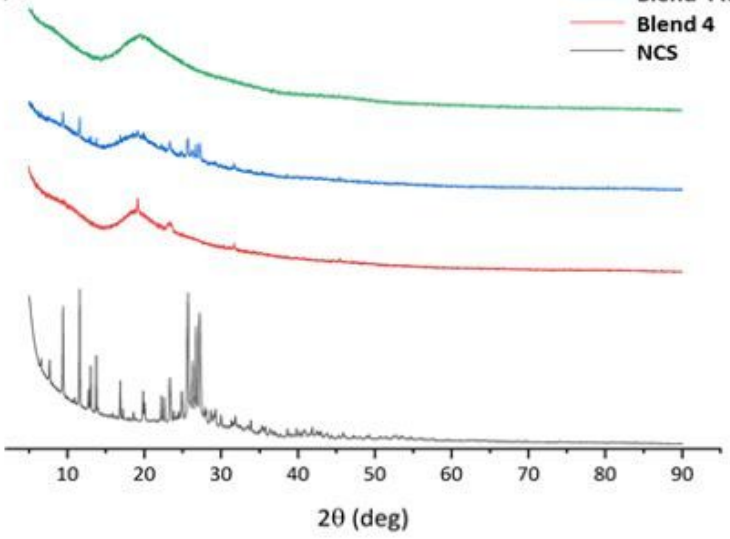

\section{Figure 10}

Diffractograms of the printed tablets 1 (A), 2 (B), $3(C), 4$ (D), each compared with the diffractograms of the NCS and the respective blends with (medicated blend) and without drug (blend). 


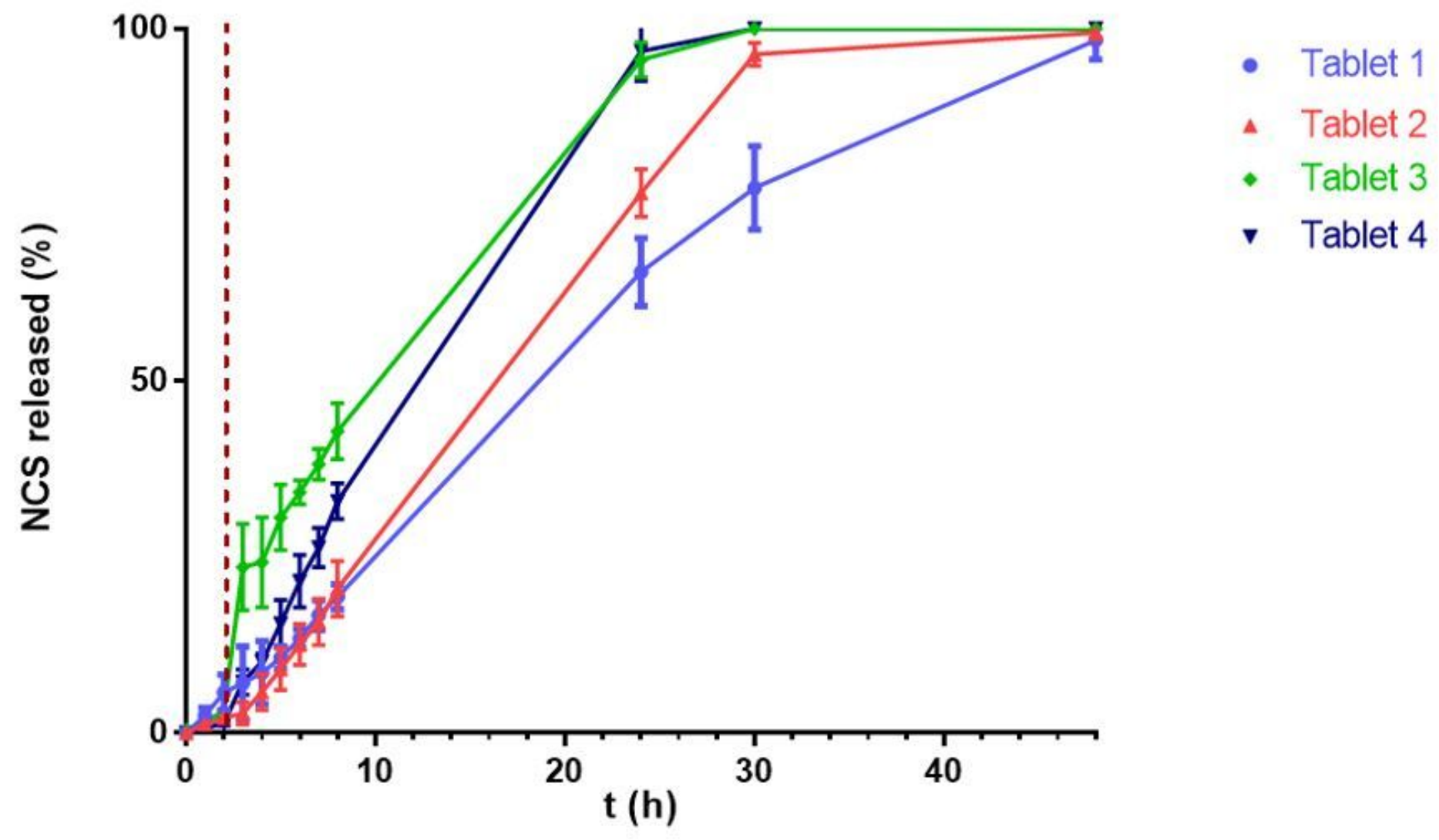

Figure 11

Dissolution profiles in gastric $(2 \mathrm{~h})$ and enteric $(46 \mathrm{~h})$ fluid of Medicated Tablets.

\section{Supplementary Files}

This is a list of supplementary files associated with this preprint. Click to download.

- graphicsabstract.jpg 